\title{
DESENVOLVIMENTO DE UM CREME ANTIOXIDANTE PARA USO DERMATOLÓGICO A PARTIR DE UM PRINCÍPIO ATIVO CONTENDO PRE/PROBIÓTICOS
}

\section{DEVELOPMENT OF A DERMATOLOGICAL GOD ANTIOXIDANT CREAM FROM AN ACTIVE PRINCIPLE CONTAINING PRE/PROBIOTICS}

\author{
Jaqueline Costa Vale ${ }^{1}$, Suzana Bender ${ }^{2 *}$ \\ ${ }^{1}$ Acadêmica de Farmácia. Centro Universitário da Fundação Assis Gurgacz (FAG). ${ }^{2}$ Docente do Centro \\ Universitário da Fundação Assis Gurgacz (FAG). \\ * Autor correspondente: suzanabender@hotmail.com, https://orcid.org/0000-0001-8913-1952
}

\begin{abstract}
RESUMO
Estudos clínicos publicados na última década sugerem que numerosas estirpes de probióticos apresentam grande potencial para o uso na dermatologia além do bem-estar intestinal já consagrado. Princípios ativos para serem incorporados em formulações dermatológicas contendo probióticos são pouco comuns. Dessa forma o princípio ativo em estudo foi um insumo original e simbiótico composto por fibras solúveis prebióticas $\beta$-frutooligossacarídeo e a-glucooligossacarídeo em conjunto com cepas de Lactobacillus inativados, atomizado em maltodextrina. $O$ objetivo da pesquisa foi verificar a viabilidade celular, as características morfo-tintoriais e bioquímicas das cepas da fração probiótica do princípio ativo e sua atividade antioxidante quando adicionado a um creme dermatológico pelo método DPPH. Em cada 1 grama do princípio ativo foram encontradas em média 4,15.109 UFC. $\mathrm{g}^{-1}$ que apresentaram características morfotintoriais e bioquímicas condizentes com as do Lactobacillus acidophilus e Lactobacillus casei. No método do DPPH, o creme dermatológico apresentou atividade antioxidante em todas as concentrações testadas e foi maior(30,8\%) na concentração de $3 \%$.Mais estudos devem ser realizados para verificar se a atividade antioxidante é proveniente também da fração prébiótica do princípio ativo. Palavras chave: Antioxidantes, Dermatologia, Probióticos.
\end{abstract}

\begin{abstract}
Clinical studies published in the last decade suggest that many probiotic strains present great potential for the use in dermatology in addition to the well-established intestinal well-being. Active principles to be incorporated into dermatological formulations containing probiotics are uncommon. Thus, the active principle under study was an original and symbiotic input composed of soluble prebiotic fibers $\beta$-fructooligosaccharide and $\alpha$-glucooligosaccharide in conjunction with Lactobacillus inativated strains, atomized in maltodextrin. The objective of the research was to verify the viability the biochemical characteristics of the probiotic fraction of the active ingredient and its antioxidant activity when added to a dermatological cream of the DPPH method. In each one gram of the active principle, 4.15.109 CFUg-1 was found that showed morphological and biochemical characteristics that were correlated with those of Lactobacillus acidophilus and Lactobacillus casei. In the DPPH method, the dermatological cream presented antioxidant activity at all concentrations tested and was higher $(30.8 \%)$ at the $3 \%$ concentration. More studies should be performed to verify if the antioxidant activity also comes from the prebiotic fraction of the active principle.
\end{abstract}

Key-words: Antioxidants, Dermatology, Probiotics 


\section{INTRODUÇÃO}

Internacionalmente os probióticos são definidos como microrganismos vivos, que quando administrados em quantidades adequadas conferem benefício à saúde do hospedeiro. Formulações orais e alimentos com probióticos são utilizados para restaurar o equilíbrio microbiano, principalmente no trato digestório e recentemente, para o tratamento de condições inflamatórias e alérgicas. Cepas específicas são capazes de modular o sistema imunológico em níveis locais e sistêmicos (CROSS,2002).

Aplicações não intestinais de probióticos são pouco investigadas, no entanto, estes microrganismos são passíveis de serem aplicados a qualquer ambiente onde exista uma microbiota normal, assim como a pele (TANNOCK,1995).Nos últimos anos autores levantaram a hipótese de um novo modelo de unificação, ou seja, eixo intestinocérebro-pele, sugerindo que a modulação da microbiota pela implantação dos probióticos poderia exercer profundos efeitos benéficos sobre a homeostase também da pele(CATENEO,2008).

Dessa forma os probióticos representam uma alternativa para o tratamento e prevenção de diversas afecções da pele (CATENEO,2008). Também são princípios ativos mais seguros ao consumidor, pois são produtos naturais com melhor tolerância e menor capacidade alergênica. Fato este que atende a demanda por este tipo de produto, denominado biocosméticos impulsionando os avanços técnicos e científicos no setor e, consequentemente, o desenvolvimento de novos cosméticos (BRINEY, 2004).

Neste sentido, o presente estudo fundamentou-se na necessidade de explorar o potencial dos probióticos para aplicação na pele, através da avaliação do antioxidante de um creme dermatológico contendo os mesmos. Este princípio ativo foi o único encontrado comercialmente para manipulação no Brasil, contendo células bacterianas intactas liofilizadas e atomizadas.

O princípio ativo em estudo foi um insumo original e simbiótico, com fibras solúveis prebióticas $\beta$-frutooligossacarídeo e a-glucooligossacarídeo em conjunto com cepas de Lactobacillus inativados, atomizado em maltodextrina. Segundo o fabricante o produto possui uma ação complementar pre/probiótica capaz de desencadear uma melhora na aparência da pele por confrontaras agressões diárias, mantendo, estimulando e reconstituindo a ecofloracutânea (SOLABIA,2009).

Ainda segundo o fabricante o ativo também teve sua eficácia atribuída aos Lactobacillus caseie acidophilus. O Lactobacillus casei, é uma espécie de bactéria lática fenotipicamente e geneticamente heterogênea. É caracterizado como microorganismo gram-positivo, não esporulado, catalase-negativo, desprovido de citocromo, anaeróbio, mas aerotolerante, ácido-tolerante e estritamente fermentativo. Devido a sua forma de bastonetes é chamado de "bacilo" e por ter a capacidade de transformar, através da fermentação o açúcar do leite (lactose) em ácido láctico, é chamado de lactobacilos (FERRERO,1996).

Já Lactobacillus acidophilus possui características muito semelhantesao Lactobacillus casei. É um bastonete gram-positivo, não formador deesporos, homofermentativo, catalase negativo, que habita comumente o tratointestinal humano. (MERCENIER,2002). O mecanismo de ação do princípio ativo, segundo o informe técnico do fornecedorébastante diversificado e compõem no mínimo uma das seguintes categorias: 1) Inibiçãode patógenos e restabelecimento da homeostase microbiana. 2) Proteção dabarreira epitelial. 3) Modulação da resposta imune. Sua atividade antioxidante nãofoi pesquisada. 
Além da inibição de microorganismos patogênicos, há estudos queprocuram verificar atividades benéficas dos probióticos na pele, como aumento dahidratação, inibição da melanogênese e antioxidação. O foco do presente trabalhobuscou verificar a capacidade antioxidante de um creme dermatológico contendo pre/probióticos, de modo avalidar essa nova vertente deestudos desse tema (KIMet al, 2015; TSAl et al,2013).

O objetivo da pesquisa foi verificar a viabilidade celular, as características morfotintoriais e bioquímicas das cepas da fração probiótica do princípio ativo e sua atividade antioxidante quando adicionado a um creme dermatológico pelo método DPPH.

\section{METODOLOGIA}

O trabalho foi do tipo prospectivo experimental, onde a atividade antioxidante de um creme dermatológico contendo pré/probióticos foi avaliada. $O$ estudo foi desenvolvido nas dependências do campus da Faculdade Assis Gurgacz (FAG), localizada na cidade de Cascavel -PR.

\subsection{MATERIAIS UTILIZADOS}

Oreativo2,2-difenil-1-picril-hidrazila (DPPH)(Sigma-AldrichCo.), ferricianeto de potássio, ácido tricloroacético, cloreto férrico, fosfato de sódio monobásico anidro e fosfato de sódio dibásico anidro (Vetec Química Fina Ltda) e metanol (Merck) utilizados no trabalho eram analiticamente puros. O princípio ativo foi adquirido da empresa Solabia. O ágar e o caldo MRS- De Man Rogosa and Sharpe (Oxoid) e o caldo TSB Tryptic Soy Broth (Acummedia) foram adquiridos na empresa Paraná Labor Comércio de Produtos e Equipamentos para LaboratórioLTDA. Os equipamentos utilizados foram: vórtex (Phoenix Luferco - AP56), centrífuga. Exc e Is a modelo 280 R (Fanem-Brasil), sonicador-ultrassom USC750 (Ultra Sonic Cleaner - Unique). As medidas de absorção foram realizadas em espectrofotômetro UV-Vis modelo 1600 (Nova) utilizando cubetas de vidro com percurso óptico de $1,0 \mathrm{~cm}$.

\subsection{ATIVAÇÃO DA FRAÇÃO PROBIÓTICA DO PRINCÍPIOATIVO}

A ativação das cepas liofilizadas dos probióticos contidas no princípio ativo foi importante para possibilitar a verificação da viabilidade celular e caracterização das cepas presentes no produto. Para ativação das cepas liofilizadas, 1 grama do princípio ativo foi transferido para tubos contendo $10 \mathrm{~mL}$ de caldo TSB (TrypticSoyBroth) $10 \%$ (v/v), os quais foram posteriormente incubados por um período de 24 horas em jarra de anaerobiose a $37^{\circ} \mathrm{C} \pm 1$, conforme metodologia de Redondo (2008).

\subsection{VIABILIDADE DA FRAÇÃO PROBIÓTICA DO PRINCÍPIOATIVO}

A viabilidade foi realizada segundo Schmitt (2014) com o objetivo de verificar quantas células viáveis o produto apresentava, pois, esta informação não constava no laudo do fornecedor. Após 24 horas de incubação foi realizada a centrifugação da cultura a 5000 rpm por 5 minutos. O sobrenadante foi descartado, e o sedimento ressuspenso em $10 \mathrm{~mL}$ de solução salina fosfatada tamponada, com posterior homogeneização em vórtex seguida de centrifugação. O procedimento foirealizado3 vezes, a fim de eliminar todo o caldo do sedimento. Posteriormente, o sedimento foi ressuspenso com $9 \mathrm{~mL}$ de solução fosfato tampão. A partir desta suspensão foram realizadas oito diluições sucessivas. A viabilidade celular foi determinada pela técnica de semeadura em profundidade, utilizando o meio ágar MRS (De Man Rogosa e Sharp). As análises foram realizadas em triplicata, com uma repetição.

Para contagem, foram utilizadas placas que apresentaram entre 30 e300 colônias, multiplicando-se o resultado individual pela respectiva diluição. Os resultados médios por diluição foram expressos em UFC. $g^{-1}$ de produto. 


\subsection{ISOLAMENTO DAS CEPAS DA FRAÇÃO PROBIÓTICA DO PRINCÍPIOATIVO}

$O$ isolamento das bactérias foi realizado a partir de ágar MRS que permitiu apenas o crescimento destes probióticos (GARCIA,1999).

\subsection{CARACTERIZAÇÃO DA FRAÇÃO PROBIÓTICA DO PRINCÍPIO ATIVO}

\section{Caracterização morfo-tintorial}

A quarta etapa consistiu na caracterização morfo-tintorial do o princípio ativo liofilizado, com o objetivo de comprovar que o mesmo continhacepas de Lactobacillus acidophilus e Lactobacillus casei. A caracterização morfológica foi realizada observando o aspecto das colônias na placa contendo meio de cultura. Já a caracterização morfotintorial foi realizada pelo método de Gram conforme Tortora (2010). Para isso foram preparadas suspensões em salina fisiológica, a partir das colônias i sol ad as .

Dessa suspensão foram preparados esfregaços em lâminas de vidro. Após coloração pelo método de Gram, foram observadas as características tintoriais das células ao microscópio óptico com auxílio de objetiva de 100X (imersão). As amostras bacterianas caracterizadas como "BACILOS" Gram positivos, aos pares, isolados ou em pequenas cadeias foram, então, caracterizadas presuntivamente como do gênero Lactobacillus spp.(GARCIA, 1999).

\section{Prova dacatalase}

Na quinta etapa foi realizada a caracterização do princípio ativo a partir da avaliação da presença da catalase, através de metodologia convencional. Uma gota de peróxido de hidrogênio a $3 \%(\mathrm{v} / \mathrm{v})$, foi adicionada, em lâmina de vidro, sobre uma colônia bacteriana, previamente identificada, a fim de se selecionar bactérias ácido-lácticas catalase-negativo com ausência de produção de bolhas (GARCIA,1999).

\subsection{ELABORAÇÃO DO CRÈME DERMATOLÓGICO}

A sexta etapa consistiu na preparação do creme dermatológico. A composição do creme está descrito na Tabela 1.

Tabela 1. Composição quantitativa e qualitativa da formulação do creme dermatológico

\begin{tabular}{lllr}
\hline Matéria prima & Concentração & Função & \\
\hline 1.Alcool cetoestearílico/ & $8 \%$ & Emulsionante & e \\
monoestearato de sorbitanoetoxilado & & agente & de \\
(20moles OE) & & consistência. & \\
2.Propilenoglicol & $5 \%$ & Umectante & \\
2.Dimeticone & $2 \%$ & Umectante & \\
2.Metilparabeno & $0,15 \%$ & Conservante & \\
1.Propilparabeno & $0,18 \%$ & Conservante & \\
2.Água deionizada & Qsp100g & Veículo & \\
\hline
\end{tabular}

* O número à esquerda designa a fase da emulsão: (1) oleosa; (2) aquosa.

O preparo consistiu no aquecimento, separadamente, fases 1 e 2 até $75^{\circ} \mathrm{C}$. Após, verteu-se fase 2 sobre fase $1 \mathrm{com}$ agitação. Diferentes concentrações do princípio ativo $(1 \% 1,5 \%, 2 \%, 2,5 \%$ e $3 \%)$ foram dispersas e adicionadas a $100 \mathrm{~g}$ de creme frio.

\subsection{DETERMINAÇÃO DA ATIVIDADE ANTIOXIDANTE DO CREME} DERMATOLÓGICO

Varredura da solução metanólica do DPPH

Foi realizada a varredura espectrofotométrica da solução metanólica do DPPH, a fim de determinar o comprimento de onda de máxima absorção da solução. A varredura foi realizada na faixade 430 a $650 \mathrm{~nm}$ com intervalo de $10 \mathrm{~nm}$. 
Avaliação da Atividade Antioxidante do creme dermatológico

A metodologia foi realizada conforme Mensor (2001) com algumas modificações. Foram pesadas $0,2 \mathrm{~g}$ de cada amostra de creme nas diferentes concentrações $(1,0 ; 1,5 ; 2,0 ; 2,5$ e $3 \%)$, as quais foram adicionadas de $1,8 \mathrm{~mL}$ da solução metanólica de DPPH50 $\mathrm{mgL}^{1}$. Em seguida, as amostras foram centrifugadas por 15 minutos e deixadas em repouso no escuro por 15 minutos.

A absorbância da solução foi mensurada em espectrofotômetro em um comprimento de onda de $517 \mathrm{~nm}$. O branco foi preparado utilizando o creme e m suasdiferentesconcentraçõesacrescidode $1,8 \mathrm{mLdemetanolsemaadiçãode} \mathrm{DPPH.}$ O controle negativo consistiu em creme base adicionado de solução metanólica de DPPH. Os experimentos foram realizados em duplicata, com uma repetição, à temperatura ambiente e ao abrigo da luz.

O percentual da atividade antioxidante foi calculado conforme a seguinte equação:

$\% \mathrm{AA}=\left[1-\left(\frac{\text { Abs: }_{\text {Amostra }}-\text { Abs }_{\text {Branco }}}{\text { Abs }_{\text {Controle }}}\right)\right] \times 100$

\subsection{ANÁLISE ESTATÍSTICA}

Após tabulação dos dados obtidos, foram calculados a média das duplicatas comum a repetição $(n=4)$ e o desvio padrão da média $( \pm S)$. Os valores encontrados para as duplicatas das amostras foram verificados estatisticamente pelo teste de variância (ANOVA) e pelo teste de Tukey usando o software SISVAR versão 5.3. As diferenças que apresentaram níveis de probabilidade menores e iguais a $5 \%(p \leq 0,05)$ foram consideradas estatisticamente significativas.

\section{RESULTADOS E DISCUSSÃO}

A importância das bactérias probióticas na manutenção e melhora da saúde humana em todas as faixas etárias estão cada vez mais comprovadas (BOTELHO et al., 2008; KOMATSU et al,2008).

Atualmente admite-se que os efeitos benéficos dos probióticos vão muito além dos relacionados com as atividades metabólicas e fisiológicas do trato gastrintestinal, incluindo pele e mucosas, onde os probióticos podem ter efeito protetor natural contra microrganismos. O conceito de probióticos começa anão serem mais restrito as bactérias que habitam o cólon, mas também as comunidades microbianas de outras partes do corpo, como pele e mucosa vaginal, onde a microbiota regional impede a proliferação de bactérias patogênicas (SOUZA et al, 2010; MARTINEZ,2008).

A nível dermatológico, novas evidências dos efeitos benéficos dos microorganismos probióticos, assim, como de aplicações de produtos simbióticos (associação de prebióticos e probióticos), estão apresentando resultados interessantes. Tem-se como exemplo, o trabalho que utilizou metabólitos Lactobacillus para reprimir a atividade patogênica oportunista de Staphylococcu sepidermidis (LAU; LIONG,2014).

\subsection{VIABILIDADE DA FRAÇÃO PROBIÓTICA DO PRINCÍPIO ATIVO}

A avaliação da viabilidade celular é importante por considerar que a microbiota bacteriana de um produto é realmente viável, ou seja, que realmente há microrganismos presentes para realizar os efeitos esperados. Através dos dados obtidos foi possível determinar que em 01 grama do princípio ativo analisado, estão presentes em média 4,15.109 UFC.g -1 $^{-1}$

As contagens das colônias não apresentaram diferenças estatísticas significativas, com coeficiente de variação de 3,52\%, como demostrado na Tabela 2. 
Tabela 2. Contagem de colônias de Lactobacillus spp.

\begin{tabular}{lc|l}
\hline Amostras & UFC.g ${ }^{-1}$ & Repetição \\
Placa1 & $4.10^{9} \mathrm{UFC} . \mathrm{g}^{-1}$ & $4.310^{9} \mathrm{UFC} . \mathrm{g}^{-1}$ \\
Placa2 & $4.5109 \mathrm{UFC} . \mathrm{g}^{-1}$ & $3.5109 \mathrm{UFC} . \mathrm{g}^{-1}$ \\
Placa3 & $3.710^{9} \mathrm{UFC} . \mathrm{g}^{-1}$ & $3.910^{-1} \mathrm{UFC} . \mathrm{g}^{-1}$ \\
Valor médio & $4.1510^{9} \mathrm{UFC} . \mathrm{g}^{-1}$ & \\
Coeficiente de variação & $3,52 \%$ &
\end{tabular}

*Ensaio realizado em triplicata com uma repetição

\subsection{CARACTERIZAÇÃO DA FRAÇÃO PROBIÓTICA DO PRINCÍPIO ATIVO}

Os resultados encontrados na avaliação das características morfo-tintorial e das provas bioquímicas estão expressos na Tabela 3 .

Tabela 3. Caracterização da fração probiótica do princípio ativo.

\begin{tabular}{|c|c|c|c|}
\hline \multicolumn{2}{|c|}{$\begin{array}{c}\text { Caracterização } \\
\text { Tintorial das colônias }\end{array}$} & $\begin{array}{l}\text { Prova da } \\
\text { Catalase }\end{array}$ & $\begin{array}{c}\text { Caracterização morfoló-gicas } \\
\text { das colônias }\end{array}$ \\
\hline $\begin{array}{l}\text { Colônia1 } \\
\text { Bacilos } \\
\text { positivos } \\
\text { Colônia2 }\end{array}$ & Gram & Negativa & $\begin{array}{l}\text { Colônias pequenas,profundas } \\
\text { ebrancas; }\end{array}$ \\
\hline $\begin{array}{l}\text { Bacilos } \\
\text { positivos }\end{array}$ & Gram & Negativa & $\begin{array}{l}\text { medianas } \\
\text { convexasamarelas }\end{array}$ \\
\hline
\end{tabular}

Após análise dos resultados e comparação com dados obtidos na literatura, foi possível concluir que foram encontrados o Lactobacillus acidophilus (colônia 1) e Lactobacillus casei (colônia2).

\subsection{AVALIAÇÃO DA ATIVIDADE ANTIOXIDANTE DO CREME DERMATOLÓGICO}

A média das absorbâncias das duplicatas com uma repetição e o desvio padrão das mesmas foram demonstrados na tabela 4.

Tabela 4. Média das absorbâncias das duplicatas com uma repetição e o desvio padrão.

\begin{tabular}{llllll}
\hline Concentração & $1,00 \%$ & $1,50 \%$ & $2,00 \%$ & $2,50 \%$ & $3,00 \%$ \\
Média & 1,00 & 0,92 & 0,90 & 0,86 & 0,82 \\
Desvio Padrão & 0,080 & & 0,052 & 0,061 & 0,019 \\
\hline
\end{tabular}

A partir dos percentuais calculados da atividade antioxidante foi construído o gráfico da porcentagem da atividade antioxidante versus concentração para cada amostra. Os resultados foram apresentados na Figura1.

Observou-se que a atividade antioxidante do princípio ativo foi dose-dependente, ou seja, demonstrou ter maior atividade antioxidante quanto maior a concentração. As formulações nas concentrações de 1,5\%,2\% e 2,5\%apresentaram atividade antioxidante superior a $20 \%$. Entretanto, entre si, estas três formulações não apresentaram diferenças estatísticas significativas. Contudo, apresentaram diferenças estatísticas na 
atividade antioxidante em comparação com as formulações que continham menor $(1,0 \%)$ e maior (3,0\%) concentração de princípio ativo.

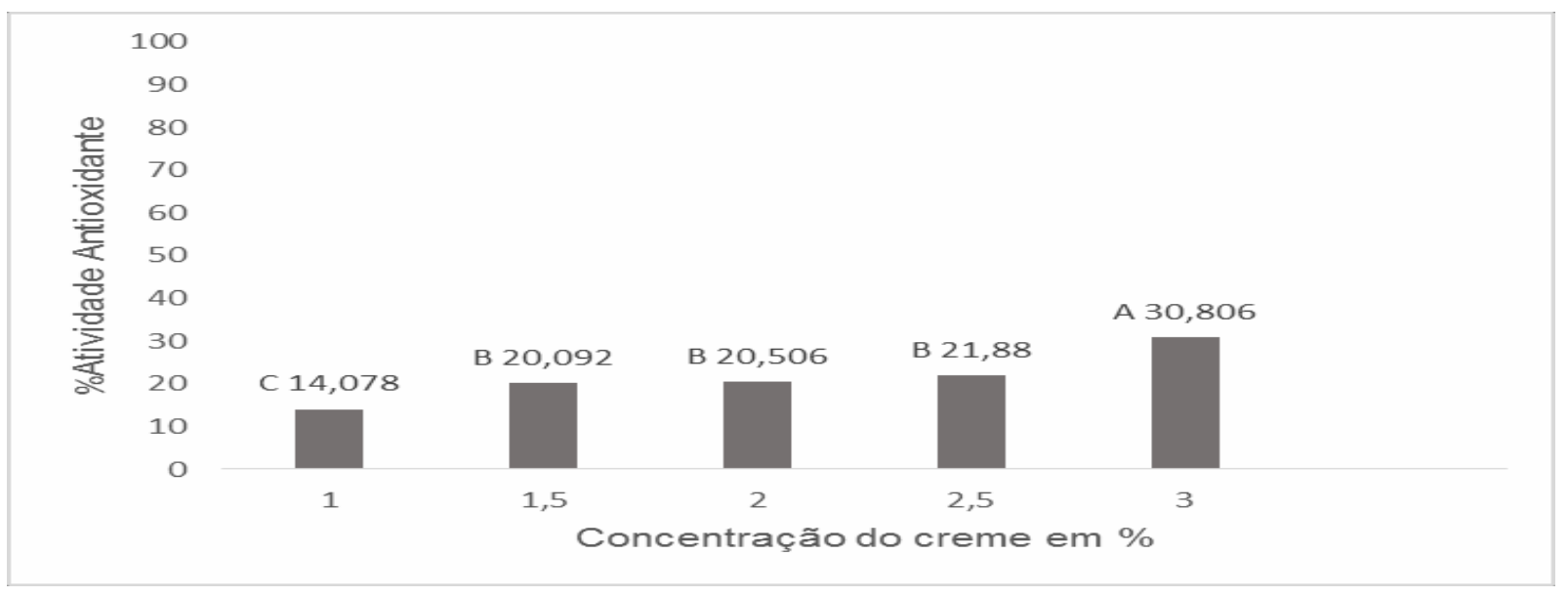

Figura 1: Porcentagem da atividade antioxidante nas diferentes concentrações do creme dermatológico. Diferenças significativas $(p<0,05)$ estão indicadas com letras diferentes.

A formulação do creme dermatológico na concentração de 3,0\% apresentou a maior atividade antioxidante $(30,80 \%)$ em relação às demais concentrações. Este resultado foi estatisticamente diferente $(P<0,05)$ em comparação com as formulações contendo concentrações inferiores.

A atividade antioxidante dose-dependente também foi observada no trabalho de Gusmão et al (2013), ao avaliarem um fluido hidratante facial contendo ácido ascórbico (vitamina $\mathrm{C}$ ), utilizando o método do DPPH. A atividade antioxidante encontrada variou de $0,2 \%$ a $1 \%$, conforme aumentou a concentração de ácido ascórbico. O sobrenadante do Lactobacillus rhamnosus em cosméticos foi avaliado nas concentrações de $10 \%$, $50 \%, 100 \%$ e comparado com o butilhidroxianisol (BHA).Nesse estudo as amostras com $100 \%$ do sobrenadante do $L$. rhamnosus apresentaram resultados muito próximos ao do BHA, que ficou em um pouco mais de $70 \%$ de atividade antioxidante. Para um estudo preliminar, o resultado obtido foi considerado promissor (TSAI et al,2013). Cinque et al. (2011) realizaram uma série de experiências, a fim de estudara atividade antioxidante de uma estirpe específica de bactéria ácido lática, a S. thermophilus S244. Extratos desta bactéria apresentaram atividade antioxidante quando comparados à uma substância utilizada como referência desta atividade (Trolox) de forma dose-dependente. Com base nestes dados os autores avaliaram ainda o efeito fotoprotetor do lisado desta bactéria e observaram que a mesma foi capaz de proteger as células humanas da radiação UV também de forma dependente. Os autores atribuíram este efeito fotoprotetor a capacidade antioxidante da bactéria.

Os probióticos podem ainda ser utilizados na ativação de compostos bioativos diminuindo o efeito alergênico de alguns princípios ativos aumentando a eficácia antioxidante, anti-melanogênese e anti-rugas (LEE et al,2012). Fries e Frasson (2010) investigaram a atividade antioxidante de quatro cosméticos anti-idade comercializados em todo o país pelo método DPPH. Os autores observaram que os cremes apresentaram atividade antioxidante, entretanto a intensidade desta ação foi diferenciada entre eles, devido aos variados compostos empregados em suas formulações. Ainda, segundo os autores, a composição dos cremes não estava especificada quantitativamente na rotulagem.

Line Yen(1999), em suas pesquisas comprovaram a atividade antioxidante dos probióticos in vitro tanto pelo método do DPPH como por outras metodologias. Este 
estudo atribuiu a atividade antioxidante das células dos lactobacilos à composição da sua parede celular.

\section{CONCLUSÃO}

O produto cosmético desenvolvido apresentaLactobacillussp. em sua composição e possui potencial para serutilizado como antioxidante. No entanto mais estudos devem ser realizados para verificar se a atividades antioxidante do produto desenvolvido não provem também da fração prebiótica do princípio ativo.

\section{REFERÊNCIAS}

AGÊNCIA NACIONALDE VIGILÂNCIA SANITÁRIA - ANVISA. Resolução RDC n² de 07 de janeiro de 2002 - Aprova o Regulamento Técnico de Substâncias Bioativas e Probióticos isolados com alegação de propriedade funcional e ou de saúde. Diário Oficial daUnião de 09 de janeiro de 2002.

BARATA, A. F. Cosméticos, Arte e Ciência. Lisboa: Lidel, 2002, 428p.

BOTELHO, L. Isolamento e identificação de lactobacilos e bífido bactérias em alimentos probióticos disponíveis no mercado brasileiro. Tese do programa de PósGraduaçãoem Alimentos e Nutrição da Faculdade Engenharia de Alimentosda Universidade Estadual de Campinas, 2005, 244p.

BRAND-WILLIAMS, W.; CUVELIER, M. E.; BERSET, C. Use of a free radicalmethodto evaluate antioxidant activity. Food Science and Technology, v. 28, 25-30,1995.

BRINEY, C. State of the industry. Global Cosmetic Industry, v. 172, 26-30, 2004.

CATANEO, C.B.; CALIARI, V.; GONZAGA, L. V.; KUSKOSKI, E. M.; FETT, R. Atividade antioxidante e conteúdo fenólico do resíduo agroindustrial da produção de vinho. Semina: Ciências Agrárias, v. 29, n. 1, p. 93-102, 2008.

CINQUE B, LA TORRE C, MELCHIORREE, MARCHESANI G, ZOCCALIG,PALUMBO P, DI MARZIO L, MASCI A, MOSCA L, MASTROMARINO P,GIULIANI M, CIFONE MG. 2011. Use of probiotics for dermal applications. Microbiol. Monogr. 21:221241.doi:10.1007/978-3-642-20838-6_9.

CROSS, M. L. Microbes versus microbes: immune signals generated byprobiotic lactobacilli and their role in protection against microbial pathogens. Immunologyand Medical Microbiology, n. 34, p. 245 - 253, 2002.

DELCOUR J, FERAIN T, DEGHORAIN M, PALUMBO E, HOLS P. The biosynthesisand functionality of the cell-wall of lactic acid bacteria. Antonievan Leeuwenhoek, 76(1):159-184, 1999. 
FERRERO, M.; CESENA, C.; MORELLI, L.; SCOLARI, G.; VESCOVO, M. Molecular Characterization of Lactobacillus caseistrains. FEMS Microbiology Letters, V. 140,n. 2-3, 215-219,1996.

FREIS, A. T.; FRASSON, A. P. Z. Avaliação Da Atividade AntioxidanteDe Cosméticos Anti-idade. Revista Contexto \& Saúde ljuí Editora Unijuí. v.10, n.19, p.17-23, 2010.

GARCIA, G. R.; SCHOCKEN-ITURRINO, R. P.; MEDEIROS, A. A.; POIATTI, M.L.; RAGAZANI,A.V.F.;HATAYDE,M.C.;CHIODA,T.P.;COAN,R.M.;PIGATTO,C. P.; TROVÓ, K. V. P. Inhibition of the growth of pathogenic bacteria byLactobacillus acidophilus. Revista Portuguesa de Ciências Veterinárias, v. 101, p. 263268,2006 .

GARCIA, S. Isolamento e caracterização de bactérias lácticas para usocomo probiótico. Tese do Programa de Pós-Graduação em Ciência dos Alimentos da Universidade Estadual de Londrina (UEL), Londrina - PR, 1999, 90p.

GUSMÃO, C.P.; SAMPAIO, P. G.; ROSSETI FILHO, P.; BIGHETTI, A. E. Estudo da atividadeantioxidante de um fluido hidratante fácil com vitamina C. In: Anais do13 ${ }^{\circ}$ Congresso Nacional de Iniciação Científica, v. 1, u. 3, p.11, 2013

KIM, H. R.; KIM, H.; JUNG, B. J.; YOU, G. E.; JANG, S.; CHUNG, D. K. Lipoteichoic acid isolated from Lactobacillus plantarum inhibits melanogenesis in B16F10 mouse melanoma cells. Molecules and cells, v. 38, n. 2, 163-170,2015.

KOMATSU, T.R.;BURITI, F. C. A.; SAAD, S. M. I. Inovação, persistência e criatividade superando barreiras no desenvolvimento de alimentos probióticos. Revista Brasileira de Ciências Farmacêuticas, v. 44, n. 3, 329-347,2008.

LAU, A. S.; LIONG, M. T. Lactic Acid Bacteria and Bifidobacteria-inhibited Staphylococcus epidermidis. Wounds, v. 26, n. 5, 121-131,2014.

LEE, H. S.; KIM, M. R.; PARK, Y.; PARK, H. Y.; CHANG, U. J.; KIM, S. Y.; SUH, H. J. Fermentingredginsengenhancesitssafetyandefficacyasanovelskincareanti- aging ingredient: in vitro and animal study. Journal of Medicinal Food, v. 15, n. 11, 10151023,2012 .

LIN, MY; CHANG, F.J. Antioxidative effect of intestinal bacteria Bifidobacterium longum ATCC 15708 and Lactobacillus acidophilus ATCC 4356. Digestive Diseases and Sciences, [s.I.], v. 45, n. 8, p. 1617-1622,. 2000.

MARTINEZ, R. C. R. Efeito da utilização de cultura láticas probióticasnamicrobiota vaginal de pacientes acometidas por infecções bacterianas e fúngicas. Tese doPrograma de Pós-Graduação Biociências Aplicadas à Farmácia da Faculdadede Ciências Farmacêuticas de Ribeirão Preto Universidade de São Paulo, 2008, 231 p. 
MENSOR, L. L. et al. Screening of brazilianplant extracts forantioxidant activityby the use of DPPH free radical method. Phytotherapy Research, v. 15, n. 2, p.127130,2001 .

MERCENIER, A., PAVAN, S., POT., B. Probiotics as biotherapeutic agents:presentknowledge and future prospects. CurrentPharmaceuticalDesign, v. 8, 99-110,2002.

NASCIMENTO, J. C.; LAGE, L. F. O.; CAMARGOS, C. R. D.; AMARAL, J. C.;COSTA, L. M.; SOUSA, A. N.;OLIVEIRA,F. Q. Determinação daatividade antioxidante pelo método DPPH e doseamento de flavonoides totais em extratosde folhas de BauhiniavariegataL. Revista Brasileira de Farmácia, v. 92, n. 4,327-332, 2011.

REDONDO, N. C. Avaliação in vitro de características probióticas doEnterococcusfaeciumCRL183 e do Lactobacillushelveticussspjugurti416. Dissertação do Programa de Pós-Graduação em Alimentos e Nutrição da Faculdade deCiências Farmacêuticas da Universidade Estadual Paulista Júlio Mesquita Filho UNESP, 2008, 1009p.

SCHMITT, I. A. D. Avaliação do perfil probiótico de cepas do Lactobacillus acidophilus destinados a aplicações farmacêuticas e alimentícias. Dissertação do Programa de Ciências Farmacêuticas da Universidade Estadual do Oeste do Paraná- UNIOESTE, 2014, 19p.

SOUZA, F. S.; COCCO, R. R.; SARNI, R. O. S.; MALLOZI, M. C.; SOLE, D. Prebióticos, probióticos e simbióticos na prevenção e tratamento dedoenças alérgicas. Revista Paulistade Pediatria, v. 28, n. 1, 86-97,2010.

SACCARO, D. M. Efeito da associação de culturas iniciadores e probióticasna acidificação, textura e viabilidade em leite fermentado. Dissertação do Programade Pós-Graduação em Tecnologia Bioquímico-Farmacêutica da Faculdade de Ciências Farmacêuticas da Universidade de São Paulo (USP), São Paulo - SP, 2008, $119 \mathrm{p}$.

SOLABIA BIOTECNOLOGIA. In forme técnico Ecoskin. Disponível em<http://www.solabia.com.br/>.Acessadoem: 15/11/14 as00:23:45

TANNOCK, G. W. et al. Identification of Lactobacillus isolatesfrom thegastrointestinal tract, silage, and yoghurt by $16 \mathrm{~S}-23 \mathrm{~S}$ rRNAgene intergenicspacer region sequence comparisons.Applied and EnvironmentalMicrobiology, Washington, v. 65, n. 9, p. 4264-4267,1999.

TORTORA, G. J; FUNKE, B. R.;.CASE, C. L. Microbiologia. 10a edição. Porto Alegre: Artmed, 2010, 964p.

TSAI,C.C.;CHAN,C.F.;HUANG,W.Y.;LIN,J.S.;CHAN,P.;LIU,H.Y.;LIN,Y.S. Applications of Lactobacillus rhamnosusspent culture supernatant incosmetic antioxidation, whitening and moisture retentions applications. Molecules, v. 18, 14161-14171 